Proceeding Paper

\title{
S. aureus and MRSA Nasal Carriage in Dental Students: A Comprehensive Approach ${ }^{\dagger}$
}

\author{
Patrícia Cavaco-Silva ${ }^{1, *}$, Maria Mole ${ }^{2}$, Beatriz Meliço ${ }^{2}$ and Helena Barroso ${ }^{1}$ (D) \\ 1 Centro de Investigação Interdisciplinar Egas Moniz (CiiEM), Instituto Universitário Egas Moniz, \\ 2829-511 Almada, Portugal; mhbarroso@egasmoniz.edu.pt \\ 2 Instituto Universitário Egas Moniz, 2829-511 Almada, Portugal; mariaanamole@gmail.com (M.M.); \\ bia.melico.97@gmail.com (B.M.) \\ * Correspondence: montezpat@gmail.com \\ + Presented at the 5th International Congress of CiiEM-Reducing Inequalities in Health and Society, Online, \\ 16-18 June 2021.
}

\begin{abstract}
Staphylococcus aureus and MRSA are important clinical pathogens representing a serious public health problem. This study aimed to determine the prevalence of $S$. aureus and methicillinresistant $S$. aureus (MRSA) nasal carriage among dental students, identify the factors that influence this carriage, and characterize MRSA. A prevalence of S. aureus and MRSA carriage of $25.2 \%$ and $0.86 \%$ was estimated, respectively, and SCCmec Type VI, was identified in all isolated MRSA. The low MRSA colonization rate can reflect good infection control practices followed by students.
\end{abstract}

Keywords: S. aureus; MRSA; nasal carriage; dental students

check for

updates

Citation: Cavaco-Silva, P.; Mole, M.; Meliço, B.; Barroso, H. S. aureus and MRSA Nasal Carriage in Dental Students: A Comprehensive Approach. Med. Sci. Forum 2021, 5, 34. https://doi.org/10.3390/ msf2021005034

Academic Editor: Cidália Castro

Published: 22 July 2021

Publisher's Note: MDPI stays neutral with regard to jurisdictional claims in published maps and institutional affiliations.

Copyright: (c) 2021 by the authors. Licensee MDPI, Basel, Switzerland. This article is an open access article distributed under the terms and conditions of the Creative Commons Attribution (CC BY) license (https:// creativecommons.org/licenses/by/ $4.0 /)$.

\section{Introduction}

Staphylococcus aureus is an important pathogen and carriage prevalence differs between populations. In dental practice, $S$. aureus transmission can occur between patients and dentists, and from contaminated surfaces and materials used during medical appointments. Therefore, monitorization of the presence of $S$. aureus, namely methicillin-resistant $S$. aureus (MRSA), in the dentistry teaching setting is important for the effective acquisition of infection and antibiotic resistance control practices [1].

\section{Materials and Methods}

A cross-sectional study was conducted in 2018 at a Dentistry University in the Lisbon Metropolitan Area, Portugal, to evaluate the prevalence of S. aureus/MRSA in dental students. Self-collected nasal swab specimens were obtained and bacterial isolates were identified using Mannitol Salt Agar, a MRSA chromogen agar and coagulase test. MRSA were confirmed with Mueller-Hinton agar $/ 6 \mu \mathrm{g} / \mathrm{mL}$ oxacillin $/ 4 \% \mathrm{NaCl}$ and cefoxitin disk diffusion test. Epidemiological molecular characterization of MRSA was performed using a multiplex PCR assay for typing of Staphylococcal cassette chromosome mec (SCCmec), important for the identification and definition of MRSA clones [2]. Data were analyzed by using descriptive and inferential methodologies; a significance level of $5 \%$ was set in the latter case.

\section{Ethics Committee Statement}

The study was conducted according to the guidelines of the Declaration of Helsinki, and approved by the Ethics Committee of Egas Moniz (protocol code 668; date of approval: 28 November 2018). 


\section{Results and Discussion}

\subsection{Prevalence of S. aureus and MRSA Nasal Carriage in Dental Students and Risk Factors}

A sample of 464 students was obtained representing $55.4 \%$ of all dental students; 117 students were colonized with $S$. aureus and 4 had MRSA isolates, thus, a prevalence of $S$. aureus and MRSA carriage of $25.2 \%$ and $0.86 \%$ was estimated, respectively. A significative statistical relationship was found between curricular year and S. aureus carriage $(p=0.05)$, showing a higher colonization rate by 4 th year students. A significative relation $(p=0.024)$ was also found between previous surgery and $S$. aureus colonization $(p=0.008)$. Additionally, male students were significantly more colonized than females $(p=0.037)$.

SCCmec Type VI was identified in all 7 MRSA isolates (four positive students) (Figure 1). SCCmec Type VI, characteristic of some MRSA clones normally associated with community infections, although less described in similar studies, matches the fact these students are starting their clinical practice [2].

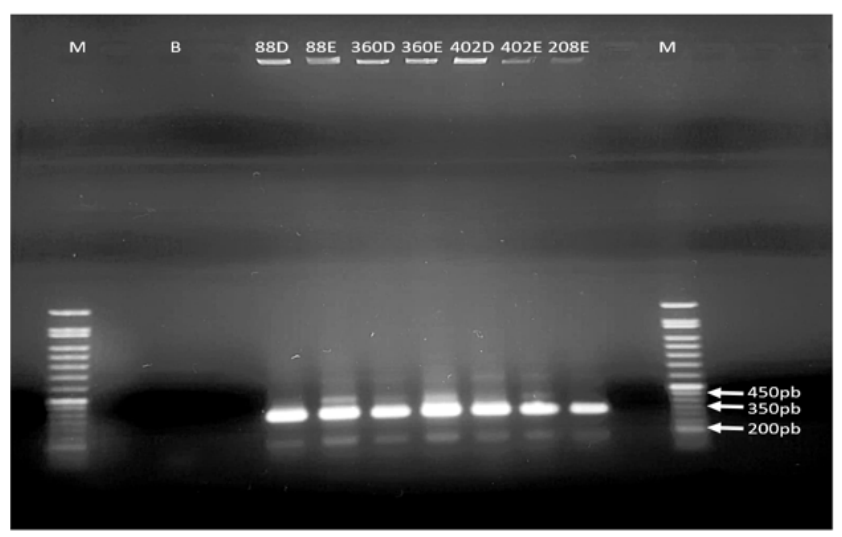

Figure 1. Agarose gel electrophoresis of products amplified by SCCmec multiplex PCR; 7 MRSA isolates from the 4 positive students (both left and right nasal cavities, except one student).

\subsection{Molecular Characterization of MRSA Isolates}

The estimated prevalence of $S$. aureus and MRSA is lower than found in other studies [1]. The higher $S$. aureus colonization rate by 4 th grade students may be justified by their first contact with patients in the clinic. The higher $S$. aureus colonization rate in male students is also common [3]. The low colonization rate of MRSA (0.86\%) can reflect good infection control practices followed by students. Additional studies would be interesting to characterize colonization patterns throughout Dentistry courses.

Informed Consent Statement: Informed consent was obtained from all subjects involved in the study.

Acknowledgments: The authors greatly thank the support of Egas Moniz teachers and students, without which this study would not have been possible.

Conflicts of Interest: The authors declare no conflict of interest.

\section{References}

1. Roberts, M.C.; Soge, O.O.; Horst, J.A.; Ly, K.A.; Milgrom, P. Methicillin-resistant Staphylococcus aureus from dental school clinic surfaces and students. Am. J. Infect. Control 2011, 39, 628-632. [CrossRef] [PubMed]

2. Lee, A.S.; de Lencastre, H.; Garau, J.; Kluytmans, J.; Malhotra-Kumar, S.; Peschel, A.; Harbarth, S. Methicillin-resistant Sthaphylococcus aureus. Nat. Rev. Dis. Primers 2018, 4, 18033. [CrossRef] [PubMed]

3. Olsen, K.; Sangvik, M.; Simonsen, G.S.; Sollid, J.U.E.; Sundsfjord, A.; Thune, I.; Furberg, A.S. Prevalence and population structure of Staphylococcus aureus nasal carriage in healthcare workers in a general population. The Tromsø Staph and Skin Study. Epidemiol. Infect. 2013, 141, 143-152. [CrossRef] [PubMed] 